\title{
Coccophagus scutellaris (Hymenoptera: Aphelinidae): A Highly Effective Biological Control Agent of Soft Scale Insects (Hemiptera: Coccidae) in Egypt
}

\author{
Shaaban Abd-Rabou \\ Plant Protection Research Institute, Agricultural Research Center, Dokki, Giza 12618, Egypt \\ Correspondence should be addressed to Shaaban Abd-Rabou, shaaban59@yahoo.com \\ Received 10 February 2011; Revised 14 April 2011; Accepted 21 April 2011 \\ Academic Editor: Ai-Ping Liang
}

Copyright (C) 2011 Shaaban Abd-Rabou. This is an open access article distributed under the Creative Commons Attribution License, which permits unrestricted use, distribution, and reproduction in any medium, provided the original work is properly cited.

\begin{abstract}
About 953000 individuals of the cosmopolitan parasitoid, Coccophagus scutellaris (Dalman) (Hymenoptera: Aphelinidae), were released and evaluated during 2009-2010 for the control of the following soft scale insects (Hemiptera: Coccidae) infesting the following economic crops in Egypt: Ceroplastes rusci on citrus in Beni Seuf, Ceroplastes floridensis Comstock on citrus in Gharbiya, Coccus hesperidum L. on guava in Giza, Pulvinaria floccifera (Westwood) on mango in Sharqiya, Pulvinaria psidii Maskell on mango in Ismailia, Saissetia coffeae (Walker) on olive in Marsa Matruh, and Saissetia oleae (Oliver) on olive in the Northern Coast. The population of C. scutellaris showed a significant correlation with the build up of the population of the soft scale insects population in all of the release sites studied. The maximum rate of parasitism of the other species of parasitoids associated with soft scale insects at the release sites decreased after the release of C. scutellaris.
\end{abstract}

\section{Introduction}

Soft scale insects (Hemiptera: Coccidae) constitute one of the most important groups of pests in agriculture. Many species are destructive especially to fruit trees and ornamentals plants. Organophosphorus insecticides have been used in an effort to control these pests; however, these products have often been ineffective, costly and have resulted in the contamination of the soil, water, and environment in the areas of Egypt that were previously unpolluted. Whereas biological control of soft scale species has been very effective, with relatively low costs and with little or no negative effects on the environment.

The genus Coccophagus Westwood (Hymenoptera: Aphelinidae) is cosmopolitan in distribution and is comprised of many of the most frequently encountered parasitoids of soft scales, several of which have been used in biological control programs [1]. Coccophagus scutellaris (Dalman) is a cosmopolitan parasitoid of various soft scale species [2] including Coccus longulus (Douglas) [3], Parasaissetia nigra (Nietner) and Parthenolecanium corni (Bouché) [4], Saissetia oleae (Oliver) and Ceroplastes floridensis (Comstock) [5] among other species. In Egypt, Priesner and Hosny [6] recorded this species associated with Coccus hesperidum L. and Pulvinaria floccifera (Westwood). Later, Abd-Rabou [7] added Pulvinaria mesembryanthemi (Vallot) and Saissetia coffeae (Walker) as coccid hosts of this species in Egypt. Bodenheimer [8] and Abd-Rabou et al. [9] recorded C. scutellaris as a common parasitoid of Coccus hesperidum and Ceroplastes floridensis.

Coccophagus scutellaris is considered to be an effective parasitoid of Saissetia coffeae and S. oleae with maximum parasitism rates of 26 and 22\% during November and August 1999, respectively [10]. Currently, it is known to attack six species of soft scales insects in Egypt and is considered to be an effective parasitoid of some of these pests. It is an autoparasitoid; the female is a primary parasitoid of soft scales and the male is a hyperparasitoid of primary parasitoids of soft scales including its own species [4]. During 2009-2010, it was reared and released in different locations in Upper Egypt [11] to control various species of soft scale insects on economic crops. The release, and establishment of 
this biological control agent in Egypt allows future studies to be conducted on its effects on the survival of soft scale insects at low population densities.

The aim of this work is to clarify the importance of rearing, release and establishment of Coccophagus scutellaris for the control of the soft scale insects and to evaluate its efficacy and the role it plays in controlling of soft scales on economic crops in Egypt.

\section{Materials and Methods}

2.1. Laboratory Rearing. The parasitoid was reared in three glasshouses. In the first glasshouse, green potato sprouts and tubers were sown in shallow trays, the bottoms of which were perforated with many holes for drainage. The trays were filled with a mixture of equal quantities of loam, sand, and peat moss and irrigated every 1-2 days. When the sprouts reached approximately $10-12 \mathrm{~cm}$ in height, eggs and crawlers of Saissetia coffeae were individually scattered on the potato sprouts in the second glasshouse conditioned at $25 \pm 2^{\circ} \mathrm{C}, 65 \%$ of relative humidity, and 14 hours of light per day. A colony of Coccophagus scutellaris was initiated in the third glasshouse with specimens that had emerged $S$. coffeae in the field and released on a culture of $S$. coffeae (5-6 weeks old). The procedures followed in the treatment experiments were also applied to the control experiment. The development from egg deposition to adult under the above mentioned thermic conditions required 34-36 days. Parasitoids emerging from field and from laboratory rearing were utilized for field releases.

2.2. Field Releases. About 963,000 adult C. scutellaris individuals were released during the period 2009-2010 on the following crops and locations: (1) citrus in Beni Seuf infested with Ceroplastes rusci, (2) citrus in Gharbiya infested with Ceroplastes floridensis Comstock, (3) guava in Giza infested with Coccus hesperidum L., (4) mango in Sharqiya infested with Pulvinaria floccifera (Westwood), (5) mango in Ismailia infested with Pulvinaria psidii Maskell, (6) olive in Marsa Matruh infested with Saissetia coffeae (Walker), and (7) olive in Northern Coast infested with Saissetia oleae (Oliver). Parasitoids were released as adults by fixing vials or cups containing these parasitoids on stems of the various hosts and allowing the adults to exit.

2.3. Assessment of Efficacy. The efficacy of released parasitoids was assessed by parasitoid emergence or dissection of their hosts. Rearing of soft scale stages was achieved by holding a total of 30 leaves each of citrus, guava, and mango and 60 olive leaves from each site in 0.5 liter cardboard containers with ventilated tops at $25 \pm 2{ }^{\circ} \mathrm{C}$ for two weeks. During 2009-2010, soft scales obtained from 7 locations in Egypt were dissected to detect prepupa and pupa of parasitoids. Samples were collected every month from October 2009 through October 2010. Three replicates of the study were performed on 14 feddan (about 0.1 hectares) of each crop. Each leaf was stored in a well-ventilated emergence

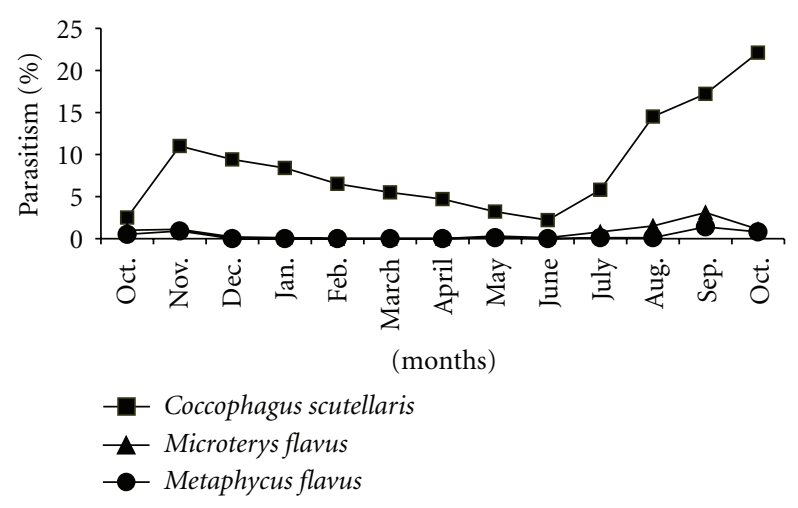

Figure 1: Percent parasitism of Coccophagus scutellaris and other associated parasitoids of Ceroplastes floridensis on citrus in Gharbiya governorate after releasing during 2009-2010.

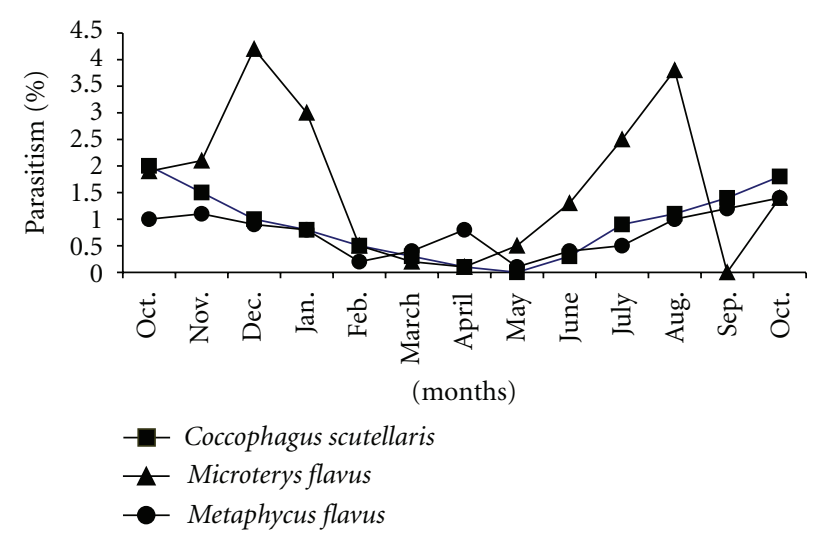

Figure 2: Percent parasitism of Coccophagus scutellaris and other associated parasitoids of Ceroplastes floridensis on citrus in Gharbiya governorate before releasing during 2009-2010.

glass tube and monitored daily for parasitism which was calculated as follows:

$$
\text { Percentage }=\frac{\text { No. } \text { parasitized }}{\text { No. } \text { parasitized }}+\text { No. unparasitized. }
$$

2.4. Statistical Analysis. Simple correlation and regression [12] origin were performed on data to determine the relationship between the populations of C. scutellaris and populations of the various species of soft scales.

\section{Results and Discussion}

The efficacy of the release of the individuals of C. scutellaris in controlling different species of soft scales on different crops and locations in Egypt was evaluated.

3.1. Ceroplastes floridensis on Citrus in Gharbiya. About 136,000 adults of C. scutellaris individuals were released during the period of 2009-2010 (Table 1). Parasitism increased after the release (Figure 1). The buildup of the population of $C$. scutellaris in the Gharbiya governorate on citrus correlated with that of $C$. floridensis $(r=0.973)$ with 


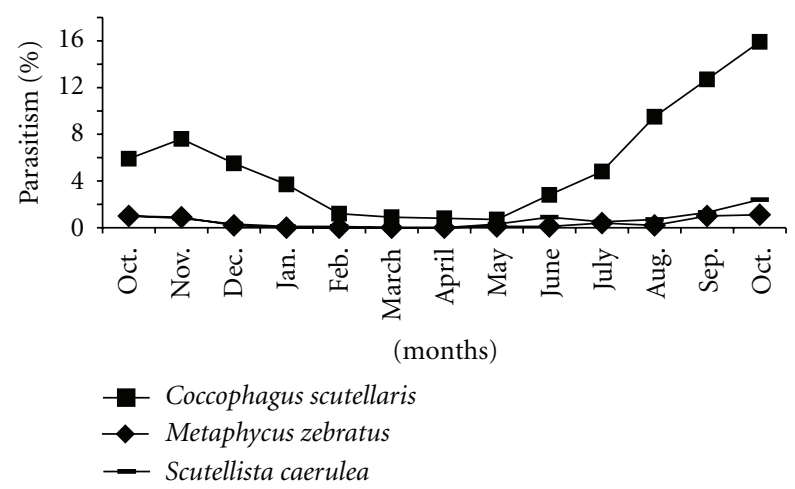

Figure 3: Percent parasitism of Coccophagus scutellaris and other associated parasitoids of Ceroplastes rusci on citrus in Beni Seuf governorate after releasing during 2009-2010.

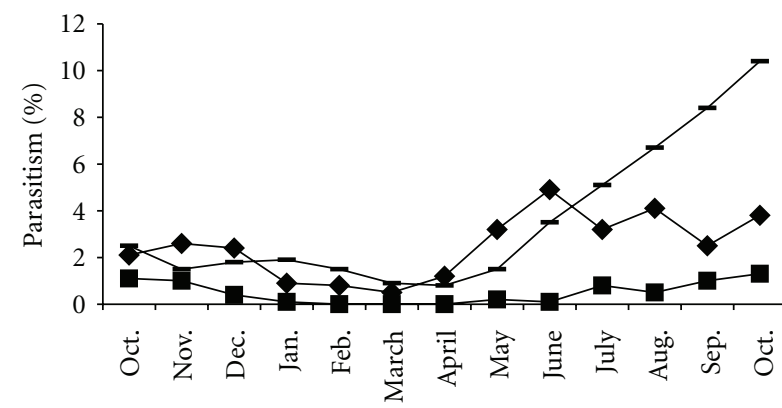

(months)

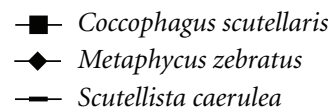

FIgUre 4: Percent parasitism of Coccophagus scutellaris and other associated parasitoids of Ceroplastes rusci on citrus in Beni Seuf governorate before releasing during 2009-2010.

simple regression values of $b=0.311, R^{2}=0.951$, and $P<.01$. Parasitism reached a maximum of $22.1 \%$ during October 2010 in the treatment plot (after release) while a maximum of $1.8 \%$ was reached during October 2009 in the control plot (before release). Parasitism by the other associated primary parasitoids Microterys flavus (Howard) and Metaphycus flavus (Howard) decreased from 1.4 to 1.1\% and from 1.4 to $0.8 \%$, respectively, after the release of $C$. scutellaris (Figures 1 and 2).

3.2. Ceroplastes rusci on Citrus in Beni Seuf. About 137,000 adult of C. scutellaris individuals were released during the period of 2009-2010 (Table 1). Parasitism increased after the release (Figure 3). The buildup of the population of $C$. scutellaris in the Beni Seuf governorate on citrus correlated with that of $C$. rusci $(r=0.813)$ with simple regression to these revealed values of $b=0.311, R^{2}=0.804$, and $P<.01$. Parasitism reached a maximum of $15.9 \%$ during Oct. 2010 in the treatment plot (after the release), while parasitism reached a maximum $1.3 \%$ during Oct. 2010 in the control plot (before the release). Parasitism by the primary parasitoid Metaphycus zebratus (Mercet) and the egg predator, Sutellista

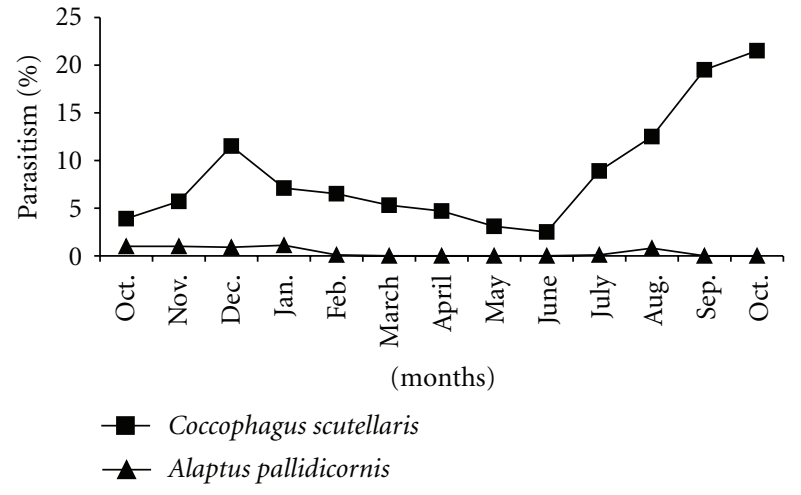

Figure 5: Percent parasitism of Coccophagus scutellaris and other associated parasitoid of Coccus hesperidum on guava in Giza governorate after releasing during 2009-2010.

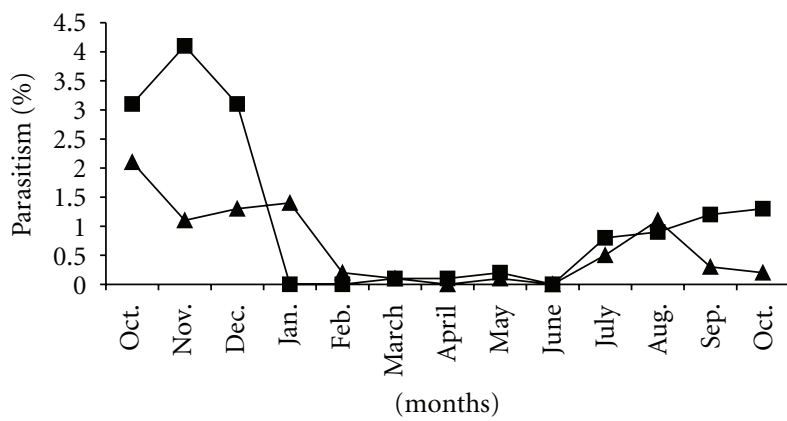

$$
\begin{aligned}
& - \text { Coccophagus scutellaris } \\
& \boldsymbol{\Perp} \text { Alaptus pallidicornis }
\end{aligned}
$$

FIGURE 6: Percent parasitism of Coccophagus scutellaris and other associated parasitoid of Coccus hesperidum on guava in Giza governorate before releasing during 2009-2010.

caerulea (Boyer de Fonscolombe), decreased from 3.8 to $1.1 \%$ and from 10.4 to $2.4 \%$, respectively, after the release of C. scutellaris (Figures 3 and 4).

3.3. Coccus hesperidum on Guava in Giza. About 138,000 adult of C. scutellaris individuals were released during the period of 2009-2010 (Table 1). Parasitism increased after the release (Figure 5). The buildup of the population $C$. scutellaris in the Giza governorate on guava correlated with that of $C$. hesperidum population buildup $(r=0.870)$ with simple regression values of $b=0.301, R^{2}=0.842$, and $P<$ .01. Maximum parasitism reached $21.5 \%$ during Oct. 2010 in the treatment plot (after release), while maximum parasitism reached 1.3\% during November 2009 in the control plot (before release). Parasitism by the egg parasitoid, Alaptus pallidicornis Förster, decreased from 1.4 to $1.1 \%$ after the release (Figures 5 and 6 ).

3.4. Pulvinaria floccifera on Mango in Sharqiya. About 127,000 adult of $C$. scutellaris individuals were released during the period of 2009-2010 (Table 1). Parasitism increased after the release (Figure 7). The buildup of the population 
TABLE 1: Total numbers of the adult parasitoid Coccophagus scutellaris released in different fields of citrus, guava, mango, olive in Beni Seuf, Gharbiya, Giza, Ismailia, Marsa Matruh, Northern Coast, and Sharqiya governorates in Egypt during each year from $2009 / 2010$.

\begin{tabular}{|c|c|c|c|c|c|c|c|}
\hline \multirow[b]{2}{*}{ Month } & \multicolumn{7}{|c|}{ No. of released parasitoids by scale insect species } \\
\hline & $\begin{array}{l}\text { Ceroplastes } \\
\text { floridensis }\end{array}$ & Ceroplastes rusci & $\begin{array}{c}\text { Coccus } \\
\text { hesperidum }\end{array}$ & $\begin{array}{c}\text { Pulvinaria } \\
\text { floccifera }\end{array}$ & $\begin{array}{c}\text { Pulvinaria } \\
\text { psidii }\end{array}$ & $\begin{array}{c}\text { Saissetia } \\
\text { coffeae }\end{array}$ & Saissetia oleae \\
\hline Oct. & 10000 & 11000 & 9000 & 11000 & 9000 & 12000 & 10000 \\
\hline Nov. & 10000 & 11000 & 8000 & 10000 & 11000 & 11000 & 10000 \\
\hline Dec. & 12000 & 10000 & 11000 & 11000 & 11000 & 11000 & 9000 \\
\hline Jan. & 11000 & 10000 & 10000 & 11000 & 10000 & 10000 & 11000 \\
\hline Feb. & 12000 & 10000 & 11000 & 11000 & 11000 & 11000 & 9000 \\
\hline March & 10000 & 11000 & 11000 & 10000 & 12000 & 11000 & 10000 \\
\hline April & 9000 & 10000 & 10000 & 11000 & 10000 & 10000 & 9000 \\
\hline May & 11000 & 10000 & 12000 & 11000 & 10000 & 10000 & 11000 \\
\hline June & 10000 & 11000 & 12000 & 10000 & 11000 & 12000 & 10000 \\
\hline July & 10000 & 9000 & 11000 & 10000 & 11000 & 11000 & 12000 \\
\hline Aug. & 10000 & 11000 & 11000 & 10000 & 12000 & 11000 & 10000 \\
\hline Sept. & 11000 & 12000 & 10000 & 11000 & 12000 & 10000 & 10000 \\
\hline Oct. & 10000 & 11000 & 12000 & 10000 & 11000 & 10000 & 13000 \\
\hline Total & 136000 & 137000 & 138000 & 127000 & 141000 & 140000 & 134000 \\
\hline
\end{tabular}

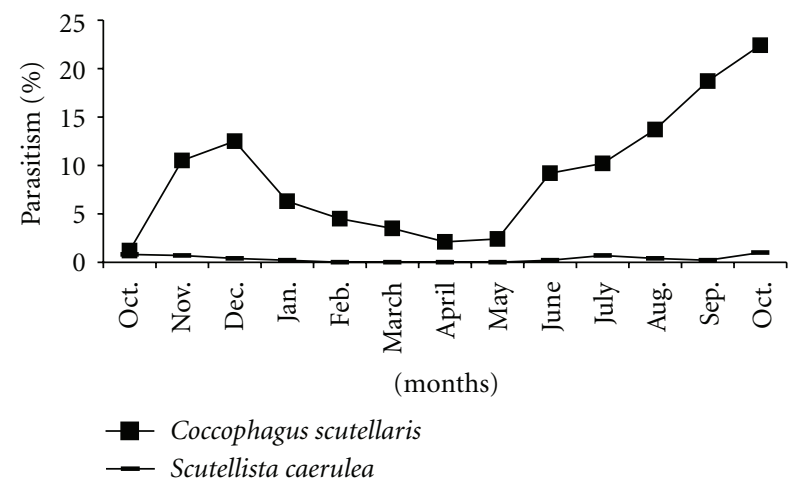

Figure 7: Percent parasitism of Coccophagus scutellaris and other associated parasitoid of Pulvinaria floccifera on mango in Sharqiya governorate after releasing during 2009-2010.

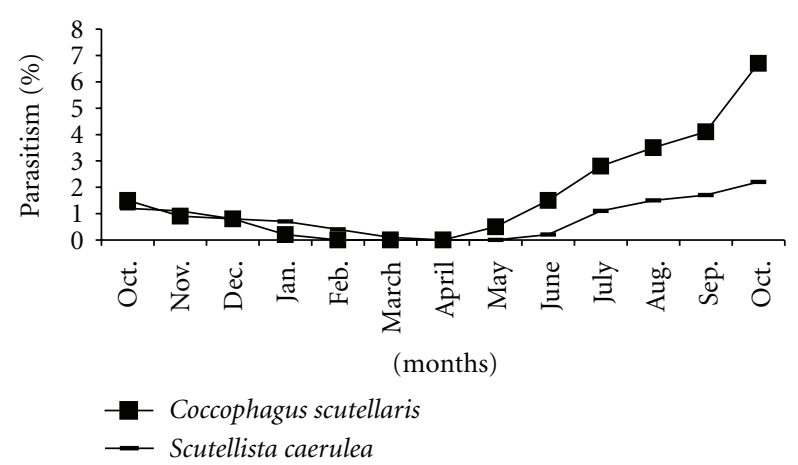

Figure 8: Percent parasitism of Coccophagus scutellaris and other associated parasitoid of Pulvinaria floccifera on mango in Sharqiya governorate before releasing during 2009-2010.

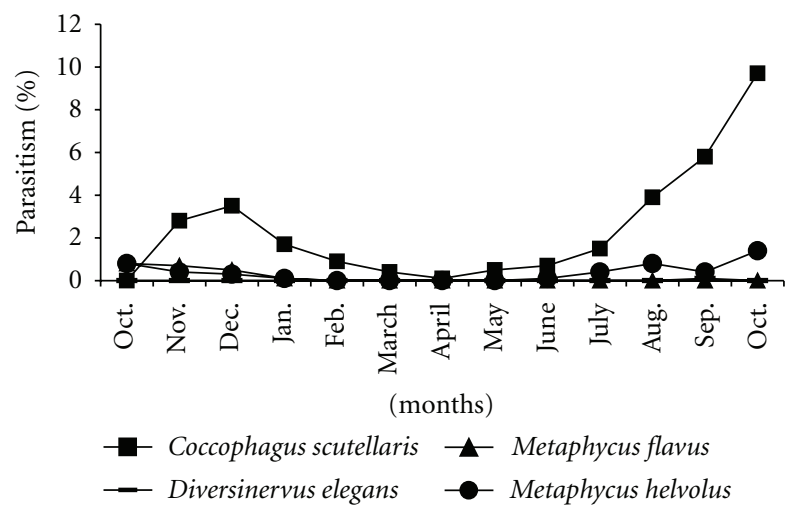

FIGURE 9: Percent parasitism of Coccophagus scutellaris and other associated parasitoids of Pulvinaria psidii on mango in Ismailia governorate after releasing during 2009-2010.

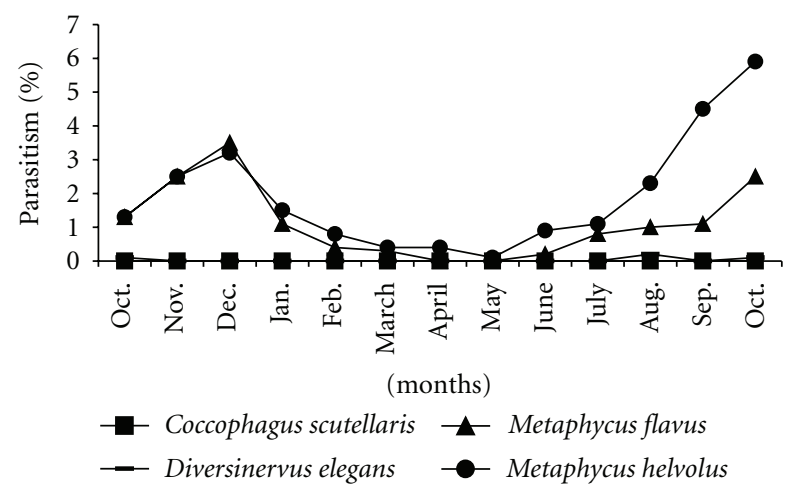

Figure 10: Percent parasitism of Coccophagus scutellaris and other associated parasitoids of Pulvinaria psidii on mango in Ismailia governorate before releasing during 2009-2010. 


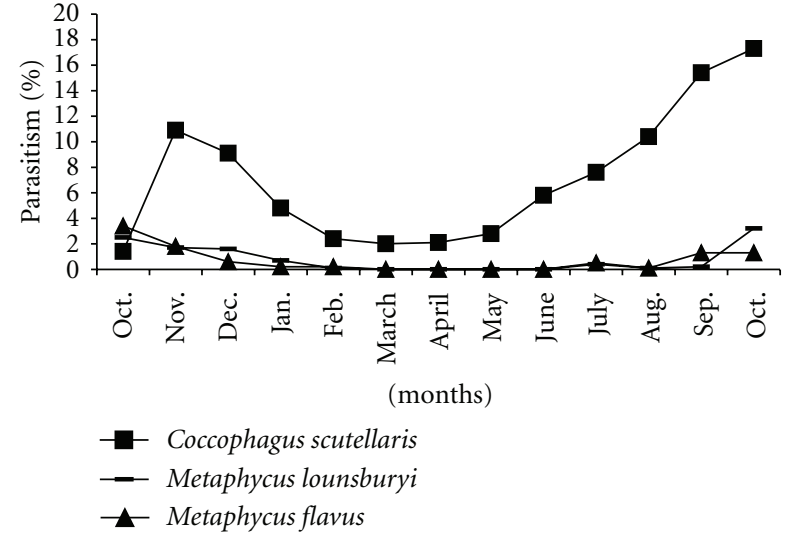

Figure 11: Percent parasitism of Coccophagus scutellaris and other associated parasitoids of Saissetia coffeae on olive in Marsa Matruh governorate after releasing during 2009-2010.

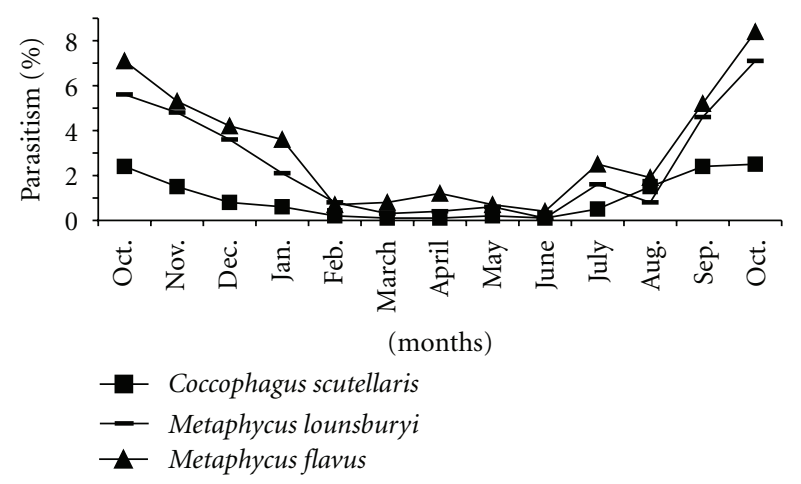

Figure 12: Percent parasitism of Coccophagus scutellaris and other associated parasitoids of Saissetia coffeae on olive in Marsa Matruh governorate before releasing during 2009-2010.

of C. scutellaris in the Sharqiya governorate on mango correlated with that of $P$. floccifera $(r=0.798)$ with simple regression values of $b=0.295, R^{2}=0.788$, and $P<.01$. Maximum parasitism reached 22.4\% during Oct. 2010 in the treatment plot (after the release), while maximum parasitism reached 6.7\% during Oct. 2010 in the control plot (before the release). Parasitism by the primary parasitoid S. caerulea decreased from 2.2 to $1.0 \%$ after the release (Figures 7 and $8)$.

3.5. Pulvinaria psidii on Mango in Ismailia. About 141,000 adults of C. scutellaris individuals were released during the period of 2009-2010 (Table 1). Parasitism increased after the release (Figure 9). The buildup of the population of $C$. scutellaris in the Ismailia governorate on mango correlated with that of $P$. psidii $(r=0.934)$ with simple regression values of $b=0.324, R^{2}=0.903$, and $P<.01$. Maximum parasitism reached $9.7 \%$ during Oct. 2010 in the treatment plot (after release), while no parasitism was observed during Oct. 2010 in the control plot (before release). Parasitism by the primary parasitoids Metaphycus flavus (Howard), M. helvolus (Compere), and Diversinervus elegans Silvestri decreased from 3.5 to $0 \%$, from 5.9 to $1.4 \%$, and from 0.2 to $0 \%$, respectively, after release (Figures 9 and 10 ).

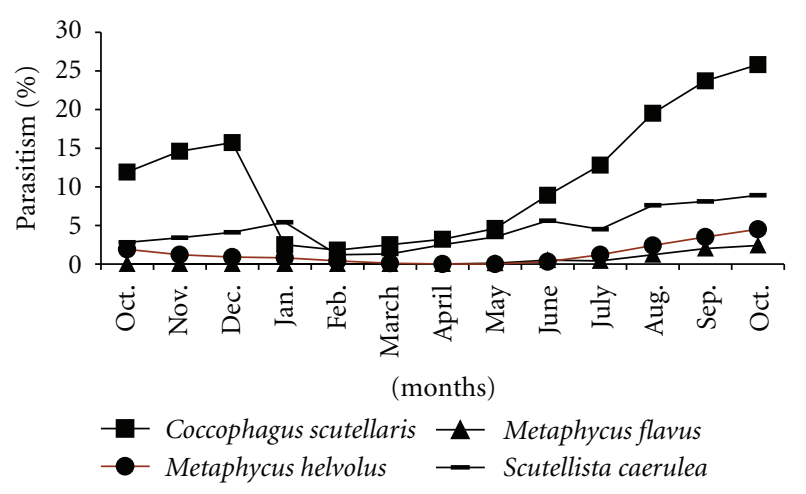

Figure 13: Percent parasitism of Coccophagus scutellaris and other associated parasitoids of Saissetia oleae on olive in Northern Coast governorate after releasing during 2009-2010.

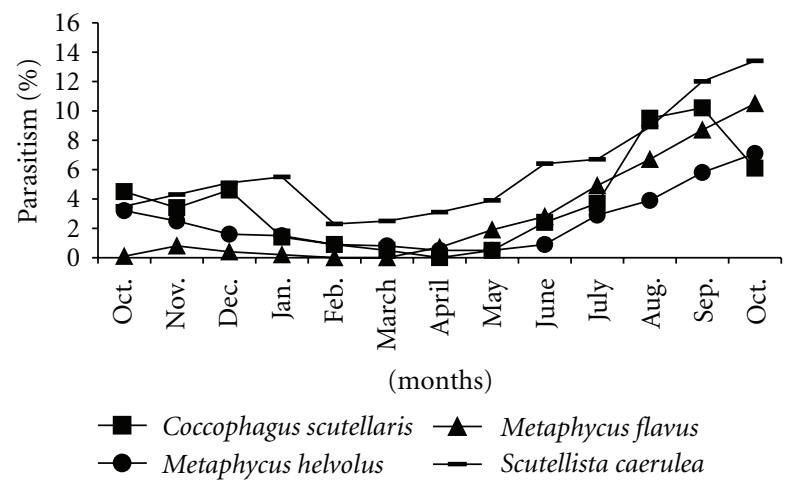

Figure 14: Percent parasitism of Coccophagus scutellaris and other associated parasitoids of Saissetia oleae on olive in Northern Coast governorate before releasing during 2009-2010.

3.6. Saissetia coffeae on Olive in Marsa Matruh. About 140,000 adult of C. scutellaris individuals were released during the period 2009-2010 (Table 1). Parasitism increased after the release (Figure 11). The buildup of the population of C. scutellaris in the Marsa Matruh governorate on olive correlated with that of $S$. coffeae $(r=0.798)$ with simple regression values of $b=0.299, R^{2}=0.787$, and $P<.01$. Maximum parasitism reached $17.3 \%$ during Oct. 2010 in the treatment plot (after release), while maximum parasitism reached 2.5\% during Oct. 2010 in the control plot (before release). Parasitism by the primary parasitoids Metaphycus lounsburyi (Howard) and M. flavus decreased from 7.1 to $3.2 \%$ and from 8.4 to $1.3 \%$, respectively, after the release (Figures 11 and 12).

3.7. Saissetia oleae on Olive in Northern Coast. About 134,000 adult of $C$. scutellaris individuals were released during the period of 2009-2010 (Table 1). Parasitism increased after the release (Figure 13). The buildup in the population of $C$. scutellaris in the Northern Coast region on olive correlated with that of $S$. oleae population buildup $(r=0.855)$ with simple regression values of $b=0.301, R^{2}=0.846$, and $P<$ .01. Maximum parasitism reached $25.8 \%$ during Oct. 2010 in the treatment plot (after the release), while maximum 
parasitism reached 6.1\% during Oct. 2010 in the control plot (before the release). Parasitism by the primary parasitoids Metaphycus flavus (Howard), M. helvolus (Compere), and the egg predator Scutellista caerulea (Boyer de Fonscolombe), decreased from 10.5 to $2.4 \%$, from 7.1 to $4.5 \%$, and from 13.4 to $8.9 \%$, respectively, after the release (Figures 13 and 14).

Results of the mass rearing showed that large numbers of this parasitoid species can be obtained by mass rearing. Parasitoids collected in areas where they are abundant and those reared in the laboratory can be transferred, distributed, and released in locations where the parasitoid is rare or not known to occur. Monthly collections of scale hosts and parasitoids were made in the release sites to monitor the population of the parasitoid where it was not previously known to exist.

The seven sites in Egypt where the parasitoids were released distinctive in their locations as well as their environmental conditions. Prior to its release, Coccophagus scutellaris was not found in Ismailia but was found in the other locations with parasitism rates ranging from 1.3 to $6.7 \%$ in control plot and from 15.9 to $25.8 \%$ in the treatment plot. After its release, Coccophagus scutellaris, was found to be established in Ismailia, with maximum parasitism rate of 9.7\% during Oct. 2010. The egg parasitoid, Alaptus pallidicornis was collected only in Giza, located south of Nile Delta, an area characterized as having high humidity. Also the parasitoid, Diversinervus elegans, was only collected in Ismailia, located on Suez Canal and Temsah Lake, which is characterized as having low humidity.

This work is an important step towards replacing the chemical insecticides currently used for controlling these soft scale species with environmentally friendly biological control agents. The control of these serious pests on economic crops in Egypt is especially important for products exported to other countries.

\section{Conclusion}

The methodology developed in amassing large numbers of the parasitoid, C. scutellaris, in the laboratory, reared or collected in the field and distributed them in areas where they are not known to occur is an effective way of establishing the parasitoid in areas where the parasitoid is needed to control soft scale species. The percentage of parasitism was satisfactory, and the population of soft scales decreased to a satisfactory level at the sites studied.

\section{References}

[1] B. M. Wilk and C. Y. Kitayama, "Host stage preference for depositon of male eggs by Coccophagus Cowperi [Hym: Aphelinaidae]," Entomophaga, vol. 26, no. 3, pp. 313-318, 1981.

[2] D. Rosen, "The hymenopterous parasites of soft scales on citrus in Israel," Beiträge Zur Entomologie, vol. 17, pp. 251279, 1967.

[3] D. P. Annecke and H. P. Insley, "The species of coccophagus westwood, 1833 from the ethiopian region (Hymenoptera: Aphelinidae)," Entomology Memoir of the Department of
Agricultural Technical Services of the Republic of South Africa, vol. 37, pp. 1-62, 1974.

[4] P. Colgan and P. D. Taylor, "Sex ratio in autoparasitic hymenoptera," American Naturalist, vol. 117, pp. 564-566, 1981.

[5] M. N. Nikol'skaja, "The chalcidoid fauna of the USSR: opred. Faun," Trudy Zoologicheskogo Instituta Akademii Nauk SSSR, vol. 44, p. 575, 1952 (Russian).

[6] H. Priesner and M. Hosny, "Notes on parasites and predators of Coccidae and Aleyrodidae in Egypt," Bulletin of the Entomological Society of Egypt, vol. 24, pp. 58-70, 1940.

[7] S. Abd-Rabou, "Parasitoids attacking soft scales (Homoptera: Coccidea) in Egypt," Egyptian Journal of Agricultural Research, vol. 79, no. 3, pp. 859-880, 2001.

[8] F. S. Bodenheimer, Citrus Entomology in the Middle East, W. Junk, The Haque, The Netherlands, 1951.

[9] S. Abd-Rabou, A. Hanafi, and N. Hussein, "Notes on the parasitoids of the soft brown scale, Coccus hesperidum (Hemiptera: Coccidae) in Egypt," Entomologica Bari, vol. 33, pp. 179-184, 1999.

[10] S. Abd-Rabou, "A survey of parasitoids associated with the hemispherical scale, Saissetia coffeae (Walker) (Hemiptera: Coccidae) in North-west Coastal area of Egypt," Bulletin of Faculty of Agriculture-University of Cairo, pp. 1-5, 2001, Special Edition.

[11] S. Abd-Rabou, "Whiteflies (Homoptera: Aleyrodidae), scale insects (Homoptera: Coccoidea) and their parasitoids in Qena governorate (Upper Egypt)," Egyptian Journal of Agricultural Research, vol. 80, no. 4, pp. 1563-1577, 2002.

[12] SAS, SAS/STAT User's Guide, version 9.1, SAS Institute, Cary, NC, USA, 2002. 

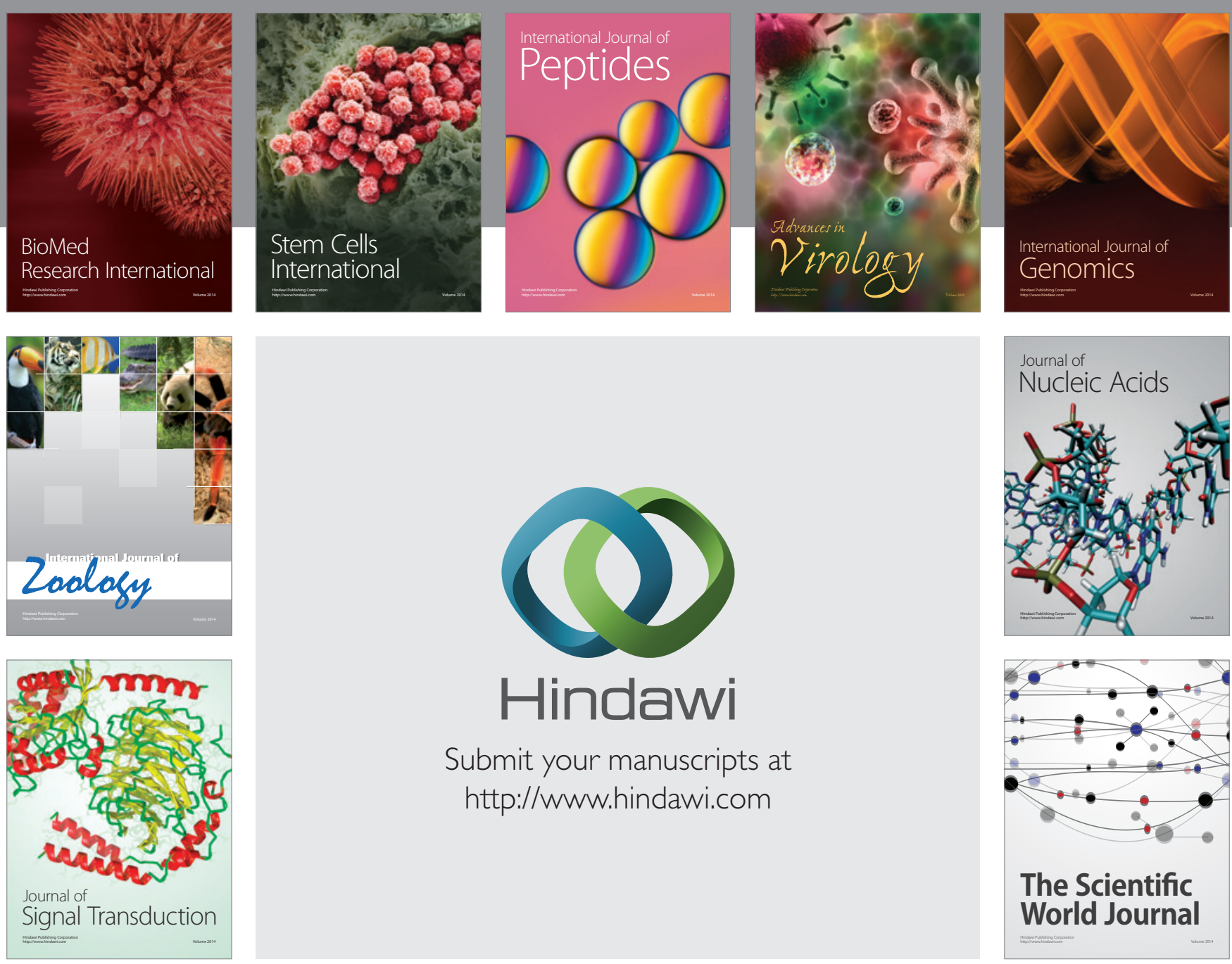

Submit your manuscripts at

http://www.hindawi.com
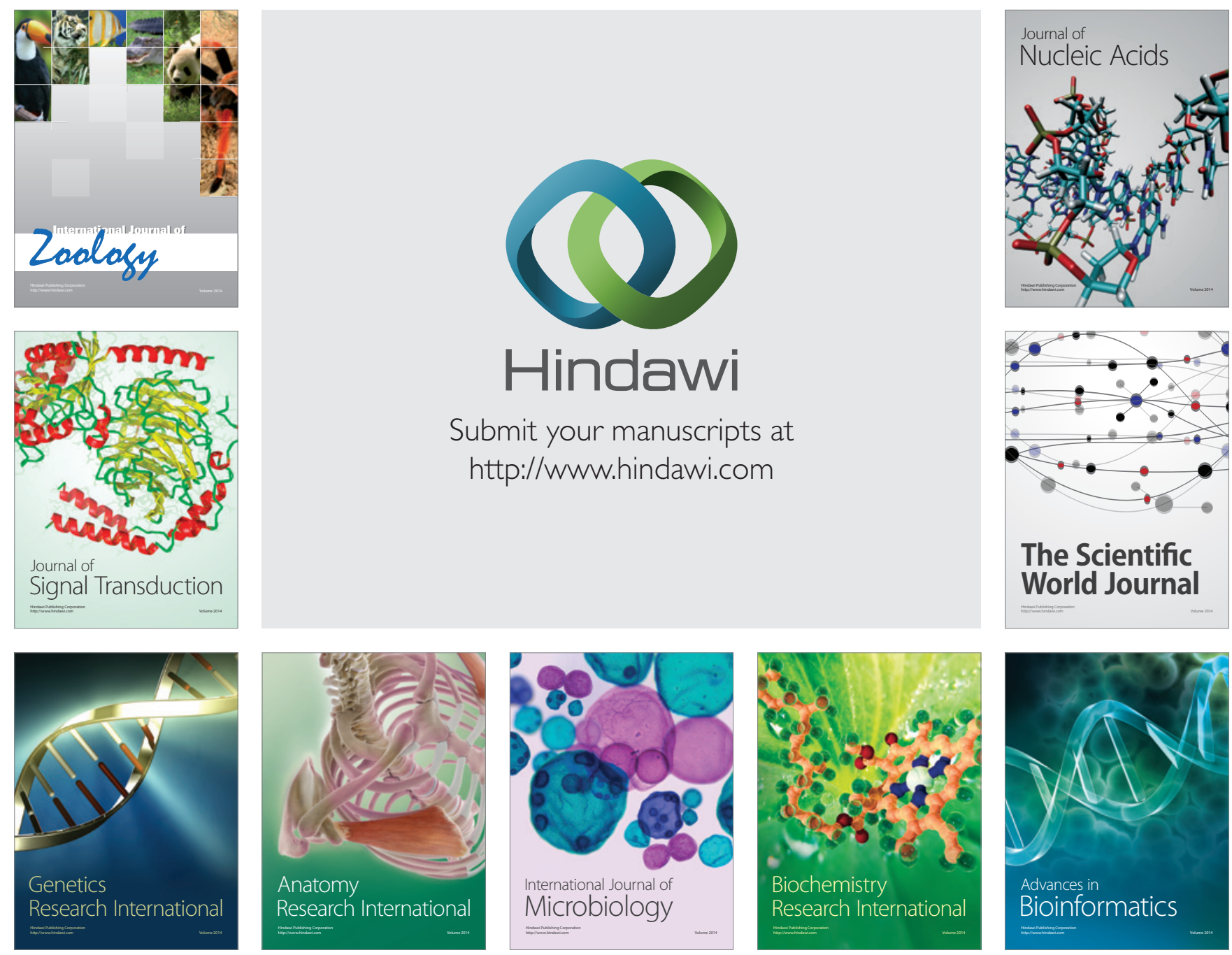

The Scientific World Journal
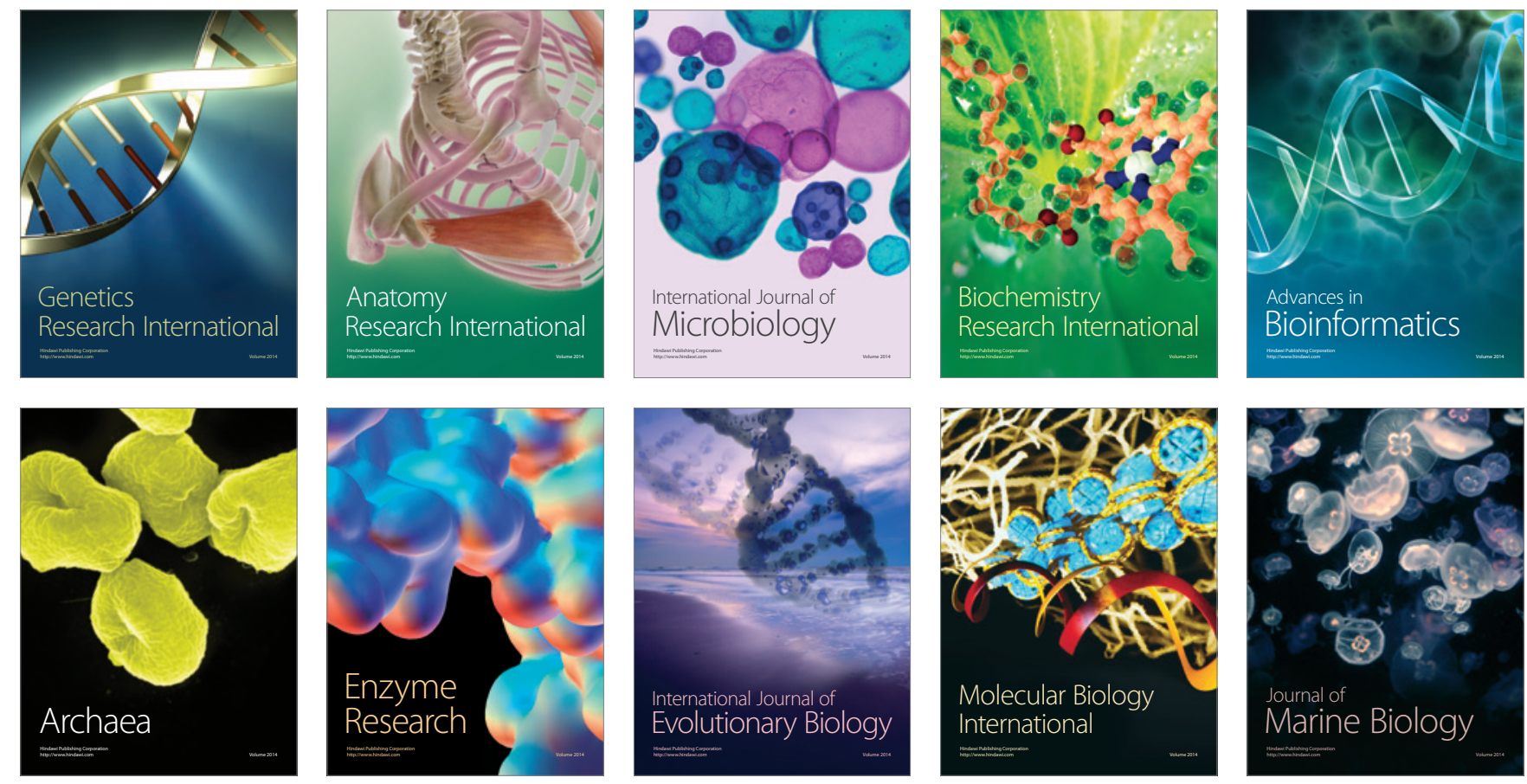